\title{
Doenças Transmissíveis de Importância no Estado de São Paulo
}

Wagner Augusto da Costa*

Apresentação do Coordenador: Conforme combinado previamente entre os participantes, a mesa teve início com a exposição do Coordenador, apresentando o quadro epidemiológico das doenças transmissíveis no Estado.

A tabela 1 (anexa) mostra o número de casos confirmados de algumas doenças de notificação compulsória no Estado de São Paulo, nos anos de 1988 a 1992.

Analisando-se a tabela, é possível identificar os seguintes grupos:

1 - Doenças que atualmente apresentam baixa incidência: Doenças geralmente, embora não exclusivamente, imunopreveníveis, como sarampo, poliomielite, difteria, etc, cujo controle, e até mesmo erradicação, é possível devido a disponibilidade de instrumentos suficientemente poderosos, de alta eficácia, capazes de interromper pontualmente a cadeia de transmissão da doença, mesmo na ausência de outras mudanças. Além das doenças imunopreviníveis, é possível citar como exemplo neste grupo as diarréias, incluindo a cólera. Devido a extensão da cobertura de água tratada para aproximadamente $90 \%$ da população, a mortalidade em decorrência de diarréias, no Estado de São Paulo, apresenta tendência de queda há vários anos. Embora haja risco de cólera, principalmente nas áreas de saneamento precário, servidas ou não por água tratada, não se espera a ocorrência de epidemias explosivas, semelhantes às que ocorreram no Peru e nos Estados do norte e nordeste do Brasil. Em São Vicente, no litoral do Estado, ocorreram casos autóctones no ano de 94, numa região extremamente precária, de alta densidade populacional e, no entanto, o número total de casos foi relativamente baixo quando comparado a situações semelhantes nas regiões citadas. A área onde ocorreram os casos, favela México 70, é abastecida com água tratada. O que chamou a atenção nesse epi-

* Centro de Vigilância Epidemiológica da Secretaria de Estado da Saúde - São Paulo. 
sódio foi a alta letalidade da doença, em torno de $10 \%$, ressaltando a má qualidade de atenção médica.

2 - Doenças com incidência alta, passíveis ou não de sofrerem alterações em decorrência de mudanças na atenção médica e/ou na organização social. Neste grupo é possível se identificar dois subgrupos:

2.1 - Doenças cujas incidências podem diminuir em decorrência apenas da melhoria da qualidade da atenção à saúde.

Doença com incidência importantes no nosso meio, como tuberculose e sífilis congênita, poderiam apresentar um quadro melhor, desde que houvesse melhora da qualidade dos serviços de saúde. Estas doenças, no entanto, não podem ser controladas com ações pontuais e necessitariam de uma melhora sensível de todo o sistema de saúde, para que de fato ocorresse diagnóstico precoce, busca ativa, controle do tratamento, visita domiciliar e outras ações. São doenças passíveis de serem controladas, mesmo com poucas ou nenhuma mudança na área social ou no meio ambiente. Evidentemente, não ignoramos os grandes avanços conseguidos no controle das doenças transmissíveis no passado, antes do aparecimento das vacinas e contimicrobianos, apenas com a melhoria das condições sociais.

2.2 - Doenças cujas incidências não seriam modificadas apenas com a melhora da qualidade de atenção médica.

Doenças como a leptospirose, AIDS (e também doenças não transmissíveis), dependem fundamentalmente de mudanças sociais profundas, para que ocorra algum reflexo positivo na incidência. As ações de saúde podem até interferir em alguns aspectos, como a letalidade, mas não tem impacto sobre a incidência. No caso da AIDS, basta lembrar a situação dramática de alguns segmentos, como por exemplo, o de mulheres migrantes, prostitutas, pertencentes às classes sociais mais baixas.

3 - Doenças com incidências importantes que dependem de melhores mecanismos de controle.

São doenças cujo risco é importante e para as quais os mecanismos de controle não são eficientes. É o caso da doença meningocócica, que permanece como um grave problema de saúde pública em áreas ou países desenvolvidos ou não. Neste grupo inclui-se, ainda, doenças causadas por novos agentes ou agentes que devido a mutações apresentam um novo perfil.

Devido a estas características, a vigilância das doenças transmissíveis continua sendo uma atividade importante e fundamental em qualquer região do mundo.

Cabe aqui uma reflexão sobre um conceito largamente divulgado. Costuma-se dizer que os países hoje desenvolvidos primeiro controlaram suas doenças infecciosas e, devido ao envelhecimento da população, voltaram suas preocupações em direção às doenças crônicas, mais comuns em faixas etárias 
maiores. Deve ser observado que as doenças crônicas também no passado causavam preocupações, embora só atualmente se disponha de melhores condições para enfrentá-las. Em relação as doenças transmissíveis, continuam sendo fonte de preocupações em qualquer país, necessitando permanentemente de novas abordagens e mecanismos de controle. Muitas destas doenças nunca chegaram a ser controladas de fato, mesmo nos países desenvolvidos que têm boa organização social.

O Dr. Luiz Jacintho abordou os possíveis mecanismos de intervenção no atual quadro epidemiológico. Há um conjunto de doenças que não representam mais o flagelo que foram no passado (doenças transmissíveis de "primeira geração" como sarampo, polio, etc). Foram doenças controladas por ações pontuais. Para uma intervenção mais moderna no atual quadro, é necessário uma mudança de visão, abandonando-se a abordagem pontual e buscando-se um controle geral.

É possível a detecção de alguns problemas importantes como:

- Resistência aos antimicrobianos: com isto há uma queda da barreira individual $X$ coletivo. Por exemplo: os Staphilococos multiresistentes não são apenas de infecção hospitalar constituindo-se num risco maior. Falta estrutura para reconhecer e enfrentar esse problema. Da mesma forma ocorre com outros agentes: meningococos, gonococos, etc. Há necessidade, portanto, de se criar uma "vigilância da resistência".

- Doenças infecciosas com grande latência. Hepatite B, C, AIDS e outras. Medidas de impacto não são suficientes e o controle ocorrerá em gerações.

- Inadequação do conhecimento sobre a transmissão, como no caso da tuberculose.

- Inadequação do conhecimento sobre a ocorrência. Há necessidade de vigilância sobre as novas doenças como hepatite $\mathrm{E}$, TB multiresistente e outras.

\section{Possíveis ações:}

- Mudança no conceito de importância: em saúde pública, em tese, todas as doenças infecciosas são passíveis de disseminação ampla; é uma questão de tempo e oportunidade. É necessário antecipar e prever.

- Aprimorar o conhecimento sobre incidência e gravidade de doenças na população. Algumas doenças já podem ser um problema sério pela distribuição e/ou pela gravidade. Por exemplo a doença causada pelo hantanvírus.

- Adequação da vigilância epidemiológica, vigiando-se "estruturas" e não suspeitos, incorporando-se técnicas diagnósticas a nível molecular, desenvolvendo-se vigilância sentinela em grupos de risco e analisando-se os cenários futuros a curto, médio e longo prazo. 
- Adequação da política de imunização introduzindo-se as novas vacinas desenvolvidas e avaliando-se o impacto da imunização no desenvolvimento de resistências aos antimicrobianos.

- Mudanças de atitude acabando por exemplo com a barreira/distinção entre problemas infecciosos de interesse hospitalar e coletivos.

\section{NÚMERO DE CASOS CONFIRMADOS DE ALGUMAS DOENÇAS DE NOTIFICAÇÃO COMPULSÓRIA NO E.S.P. - 1988 A 1992}

\begin{tabular}{lrrrrr}
\hline & & & ANO & \\
DOENÇA & 1988 & 1989 & 1990 & 1991 & 1992 \\
\hline A I D S & 2302 & 2801 & 4253 & 5585 & 6778 \\
DENGUE & - & - & 3033 & 3655 & 38 \\
DIFTERIA & 34 & 23 & 29 & 13 & 08 \\
D. MENINGOCÓCICA & 1009 & 1206 & 1430 & 1470 & 1490 \\
HANSENÍASE & 3337 & 3177 & 3280 & 3124 & 2977 \\
LEPTOSPIROSE & 509 & 445 & 361 & 901 & 409 \\
POLIOMIELITE & 05 & 02 & - & - & - \\
SARAMPO & 419 & 1503 & 873 & 339 & 160 \\
TÉTANO NEONATAL & 05 & 01 & 02 & 01 & 01 \\
TRACOMA & 37 & 1184 & 1409 & 10079 & 6146 \\
TUBERC. PULMONAR & 13286 & 12450 & 13736 & 14480 & 13957 \\
\hline
\end{tabular}

Fonte: Centro de Vigilância Epidemiológica - "Prof. Alexandre Vranjac" - CVE. 